\title{
David Hilbert, Alan Turing, the Entsheidungsproblem, and the future of loess research
}

By comparing the problems of higher mathematics and those of the earth sciences, the author recognizes the importance of the balance between the scientific question and the answer. Earth scientists generally approach the solution part of the scientific process quite well, although we do not grasp as thoroughly as we might the questioning part of the process. In addition, each of us should be questioning how our separate parts of the earth sciences fit together as a part of the whole discipline.

Even though the nature of the earth sciences causes us to find answers before questions, the author poses 10 important, basic questions in the field of loess research. Hopefully, some of the questions will not only advance the study of loess but will show us as well how loess studies fit into the whole of the earth sciences. (Ed.)

\section{Mathematics}

I have been reading the biography of Alan Turing (mathematician and computer pioneer) by Andrew Hodges (1983), and I begin to think that it may be possible to make a very tentative connection between Turing solving the Entsheidungsproblem and the much more ordinary and down-to-earth problems of loess, a connection (maybe) between the problems of higher mathematics and those of the superficial earth sciences. The 1937 Turing paper on "computable numbers" put in place onevo the philosophical foundations of the modern computer world and was one of the great intellectual achievements of the century. Its full title is "On Computable Numbers, With an Application to the Entsheidungsproblem" (Turing, 1937), and it changed the way we think about the nature of mathematics.

The Entsheidungsproblem belongs to David Hilbert, the most famous mathematician of recent times. At the 1928 International Mathematical Congress, Hilbert raised a series of questions. First, was mathematics complete in the technical sense, so that every statement (such as, "every integer is the sum of four squares") could be either proved or disproved? Second, was mathematics consistent in the sense that the statement " $2+2=5$ " could never be arrived at by a sequence of valid steps of proof? And thirdly, was mathematics decidable? By this he meant, did there exist a definite method that could, in principle, be applied to any assertion and that was guaranteed to produce a correct decision as to whether that assertion was true?
It was this third problem that Alan Turing solved by inventing the Turing machine, by inventing a new way of solving mathematical problems. The machine did not exist; it was an imaginary machine, a conceptual machine. By imagining this machine, one of the basic problems of mathematics was solved and Turing triumphed. But, of course, Turing did not triumph in a vacuum - for Turing to generate a solution, Hilbert had to pose a problem. Hilbert's problem was a precondition for Turing's solution, and it is this duality that strikes me, this balance between the question and the answer. Thus, Hilbert's genius allows the question to be posed, and Turing's genius allows it to be solved.

\section{Earth sciences}

But what has all this to do with the earth sciences and with loess in particular? Well, it might be a good idea if we gave more thought to the idea of setting ourselves a few broad, but specific, problems, a few targets. We operate and control the solution part of the scientific process quite well, but we have not grasped as thoroughly as we might the questioning (Hilbertian) part of the process. Perhaps we should have a "program." In 1900 David Hilbert put forward a list of 23 problems to be tackled by mathematicians during the 20 th century, and earlier there was the famous "Erlanger" program, set out by Felix Klein when he took up the chair at the University of Erlangen in Germany in 1872. Of course, mathematics is much more a manmade discipline than geology; that is, man sets most of the constraints and boundaries for mathematics, whereas ours are largely set by the planet we investigate. And perhaps mathematicians (like Hilbert and Klein) are more disposed to making lists. Even so, we know enough about the world machine for each of us to be questioning how our separate parts of the earth sciences fit together to form the whole. Presumably that was what Hilbert was doing-trying to see the whole picture of mathematics.

If one can come up with a brilliant question, will it provoke a brilliant answer? Earth scientists have found some brilliant answers in the past, but occasionally before the questions were posed. The idea of continental drift was a great answer that was around for a long time before anyone would accept the question. The nature of geology - and of all the earth sciences - is such that we tend to find answers before questions.

\section{Questions for loess research}

$T_{\text {phe one region in which I feel reasonably competent to offer a few }}$ basic questions is in the field of loess research. So here are 10 questions for the last part of the 20th century: the Leicester program of 


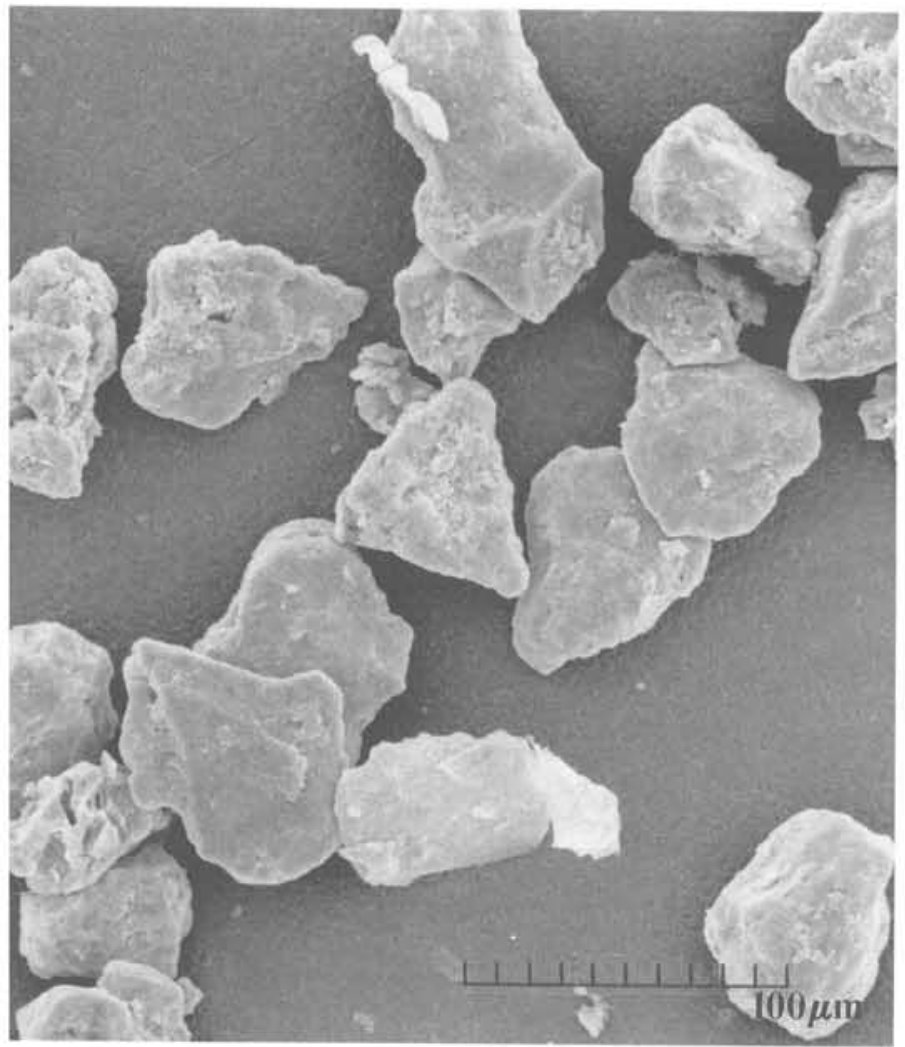

Figure 1.-Loess particles from Jiuzhoutai near Lanzhou in the western part of the Chinese loess region. How were the particles formed? Where did they form? How did they get to Jiuzhoutai? Scanning electron microscope picture by Nabil Al-Haifi.

loess research. Hopefully, some of the questions show how loess studies can be tied to other parts of the earth sciences program, the "big picture."

(1) Is loess definable? The old Smalley and Vita-Finzi (1968) definition has worked well for 20 years, but there is still a problem of reconciling the descriptive and mechanistic approaches to the task of defining the material and the deposit. Should we define loess material and loess deposit? Is loess a soil? Is loess a rock?

(2) What is the status of the quartz in the igneous source rock and in other types of source rock? How does the nature of the quartz in the source rock influence the formation and nature of the eventual loess particle?

(3) What actions cause particle formation (fig. 1), and which are the most effective? This seems to be a very important question: how are the quartz particles made by natural processes? This is a fairly recent question that was not asked seriously before 1966. And although some resolution has occurred since then, it should stay on the list of current queries. It could be cast in the form: what sources of energy are there in the natural system that can generate large amounts of coarse quartz silt?

(4) What is the initial transportation mode of a loess particle? Which transportation modes are most effective in distributing loess material (fig. 2)? Although aeolian processes confer many character-

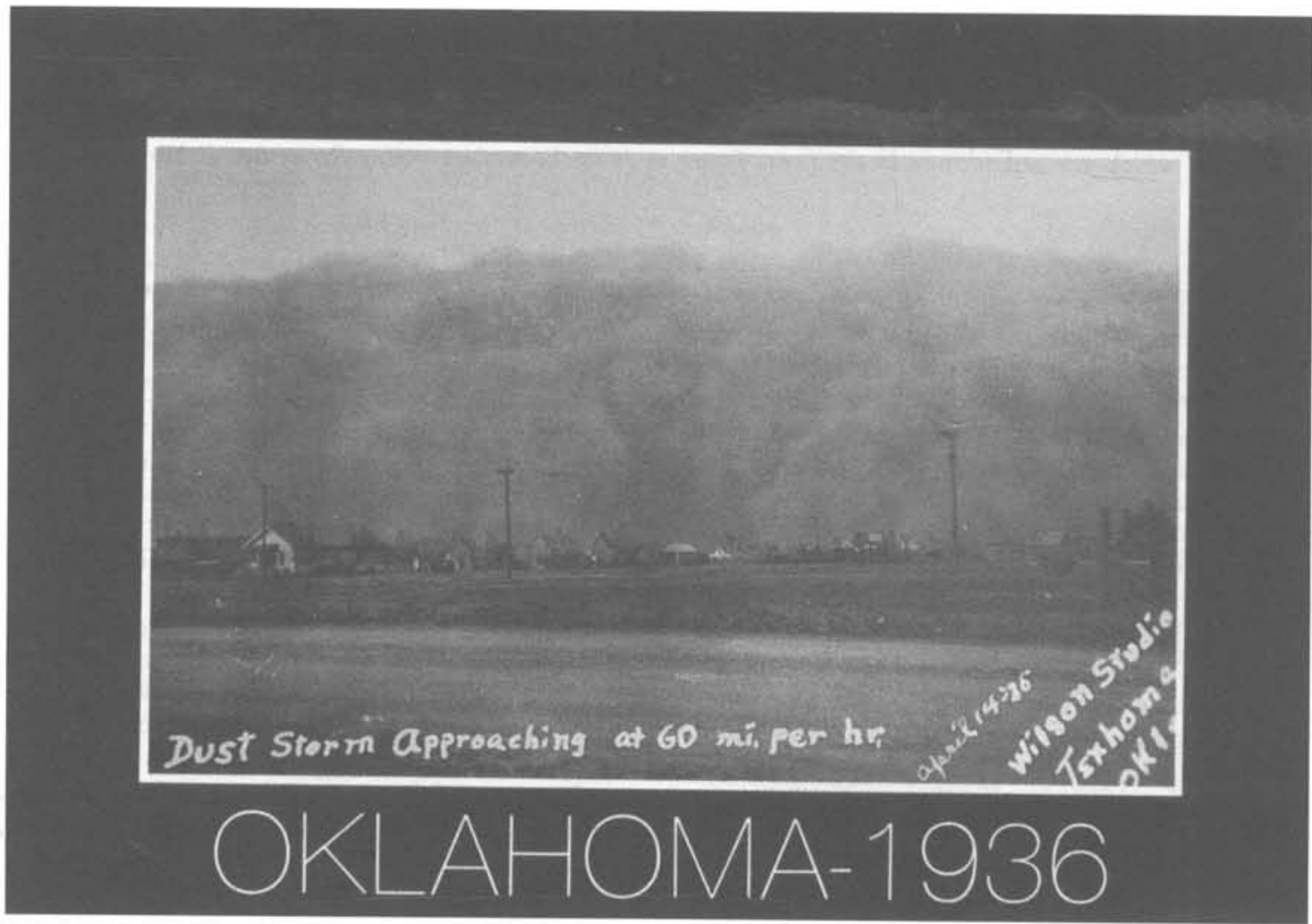

Figure 2. - Postcard of a dust storm in Oklahoma, USA. In the "Dust Bowl Era" of the 1930s, much of the loess soil material, which had blown into place as the last cold phase ended, was blown away again. The event was traumatic, and the postcards are still on sale in the 1990s. Postcard supplied by Vance Holliday. 


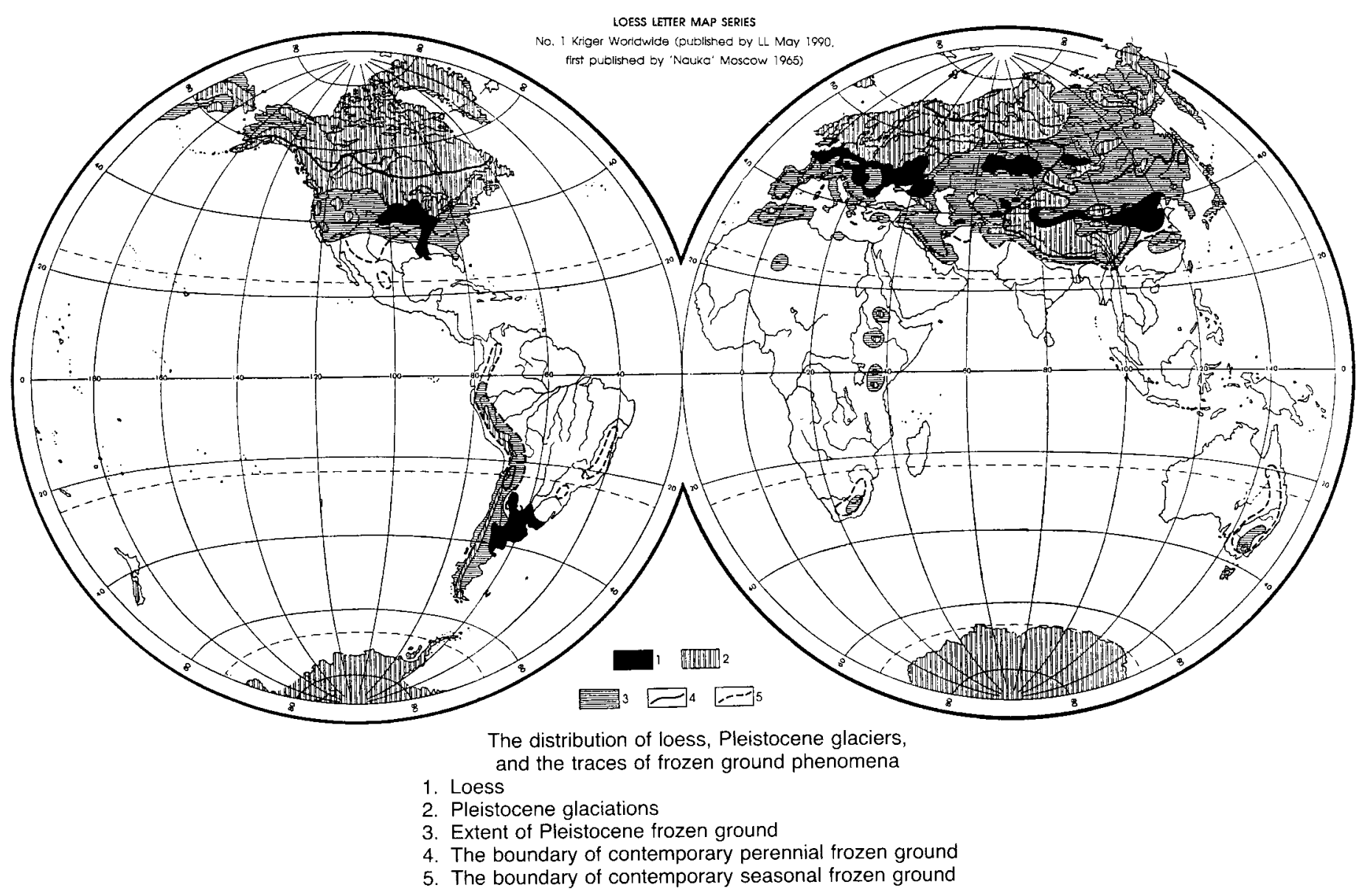

Figure 3. - Kriger map showing the world distribution of loess deposits, as seen from Moscow, USSR. This is part of N.I. Kriger's 1965 map of loess distribution, which was republished by the Loess Letter in 1990 (Loess Letter Map Series no. 1, May 1990).

istics on a loess deposit, the actual distribution of the material probably is achieved more effectively by fluvial processes.

(5) At what stage is carbonate material incorporated, and how about clay minerals? Keilhack (1920) was very puzzled that quartz and carbonate could be the main constituents of loess: "Das Rätsel der Lössbildung." Does most of the carbonate come in with the ground water in solution. or is it delivered in clastic form by aeolian processes?

(6) Can we describe the packing structure in a loess deposit? The open structure is characteristic of the most typical loess, but will it ever be possible for us to describe the packing in real terms and perhaps also to describe the collapse process?

(7) How does climatic change affect a loess deposit (fig. 3)? Does it affect the make, move, place, and change events, either all or some of them? If some, which? Liu and Chang (1964) made the dramatic discovery in the late 1950 s that loess carried an accurate imprint of multiple climatic changes through the Pleistocene, and this was the major loess "event" of recent times. The question of how the system actually responds to climatic change is still open.

(8) What are the important postdepositionary events? How do fragipan horizons form in loess deposits, and do fragipans favor loess deposits? Do Chernozems favor loess deposits, or are they totally climatically controlled? Interesting events occur after the forma- tion of the basic loess deposit, and we still need to define and explain them. How do concretions form? Why do they form discrete horizons?

(9) Is there a fundamental question on the engineering aspects of loess? Perhaps we can find the solution to the collapse problem, or a guaranteed way of building on collapsing loess, or maybe a way to prevent the large flowslide-type failures observed in Gansu Province in the People's Republic of China (PRC). Can we find a way to prevent gullying, or to reduce soil erosion in loess soils, or to make better loess bricks?

(10) As for fauna, the long loess sections in northern PRC and in central Asia (fig. 4) have a rich fossil fauna. Can we equate loess and horse? The Chinese loess stands on the Hipparion clay, so should we think of loess time as horse time and is there a connection? What evolutionary opportunities does loess offer?

The questions are important. We should look constantly for new ways of examining our subject, and there may be levels of complexity that we have never imagined. Who would have thought that a 100 -m-thick loess deposit could suggest up to 18 major climatic variations in the Pleistocene? We had all been taught that there were only four. We need intuitions, insights. . . David Hilbert, right at the beginning of "Foundations of Geometry" quoted Immanuel Kant: "All human knowledge begins with intuitions, thence passes to con- 


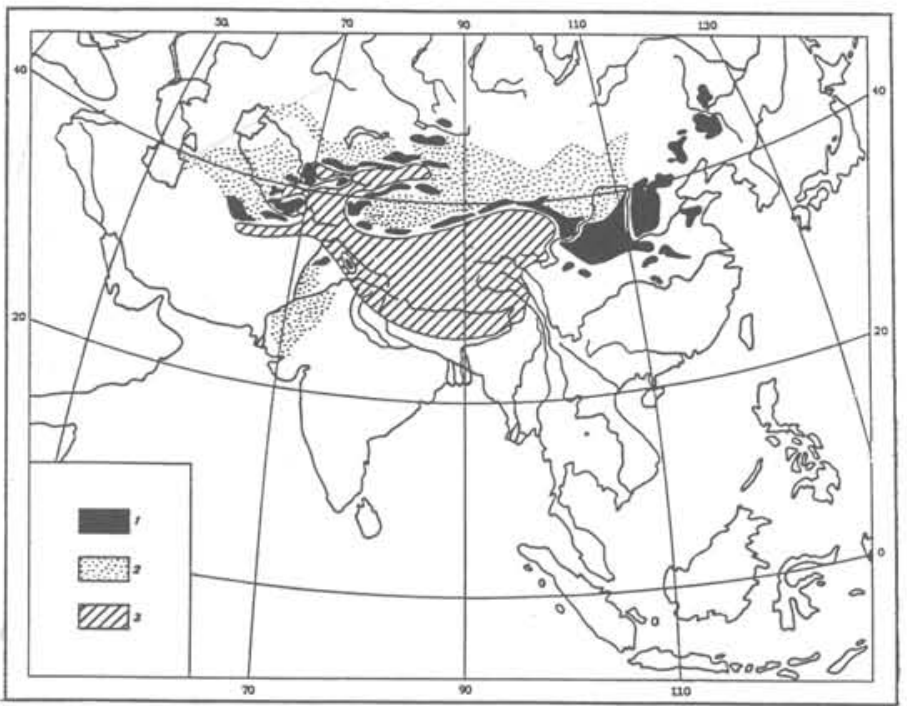

1. Loess cover

Sketch map of the distribution of loess in central Asia

2. Sandy deserts

3. Mountains uplifted to a height of more than $3,000 \mathrm{~m}$ (data for China from Liu Tung-sheng "Loess and the Environment" Beijing 1985)

Figure 4.-Alekseev-Dodonov map showing loess in the uplifted region of central Asia. Where did the loess material come from? How were the deposits formed? The 1989 map by M.N. Alekseev and A.E. Dodonov of the Soviet Academy of Sciences was republished by the Loess Letter in 1990 (Loess Letter Map Series no. 2, May 1990).

cepts and ends with ideas." Karl Caesar von Leonhard (fig. 5) had an intuition in Heidelberg, Germany, early in the 19th century, that the yellowish material he observed on the banks of the River Neckar at Haarlass was important and was sufficiently different from the rest of the Earth's surface materials to deserve a name, an identity (see Smalley, 1980 , p. 44 , for more details). Then followed: how was it formed? What does it tell us....?

\section{References}

Hodges, Andrew, 1983, Alan Turing: The enigma: London, Burnett Books, $587 \mathrm{p}$.

Keilhack, K., 1920, Das Rätsel der Lössbildung: Zeitschrift der Deutschen Geologischen Gesellschaft, v. 72, p. 146-161.

Liu Tung-sheng and Chang Tsung-hu, 1964, The "Huangtu" (loess) of China: International Union for Quaternary Research Congress, 6th, Warsaw, 1961, Report, v. 4, p. 503-524.

Smalley, I.J., 1980, Loess, a partial bibliography: Norwich, UK, Geo Books, $103 \mathrm{p}$.

Smalley, I.J., and Vita-Finzi, C., 1968, The formation of fine particles in sandy deserts and the nature of "desert" loess: Journal of Sedimentary Petrology, v. 38, p. 766-774.

Turing, A.M., 1937, On computable numbers, with an application to the Entsheidungsproblem: Proceedings of the London Mathematical Society, v. 2, p. $42-53$.

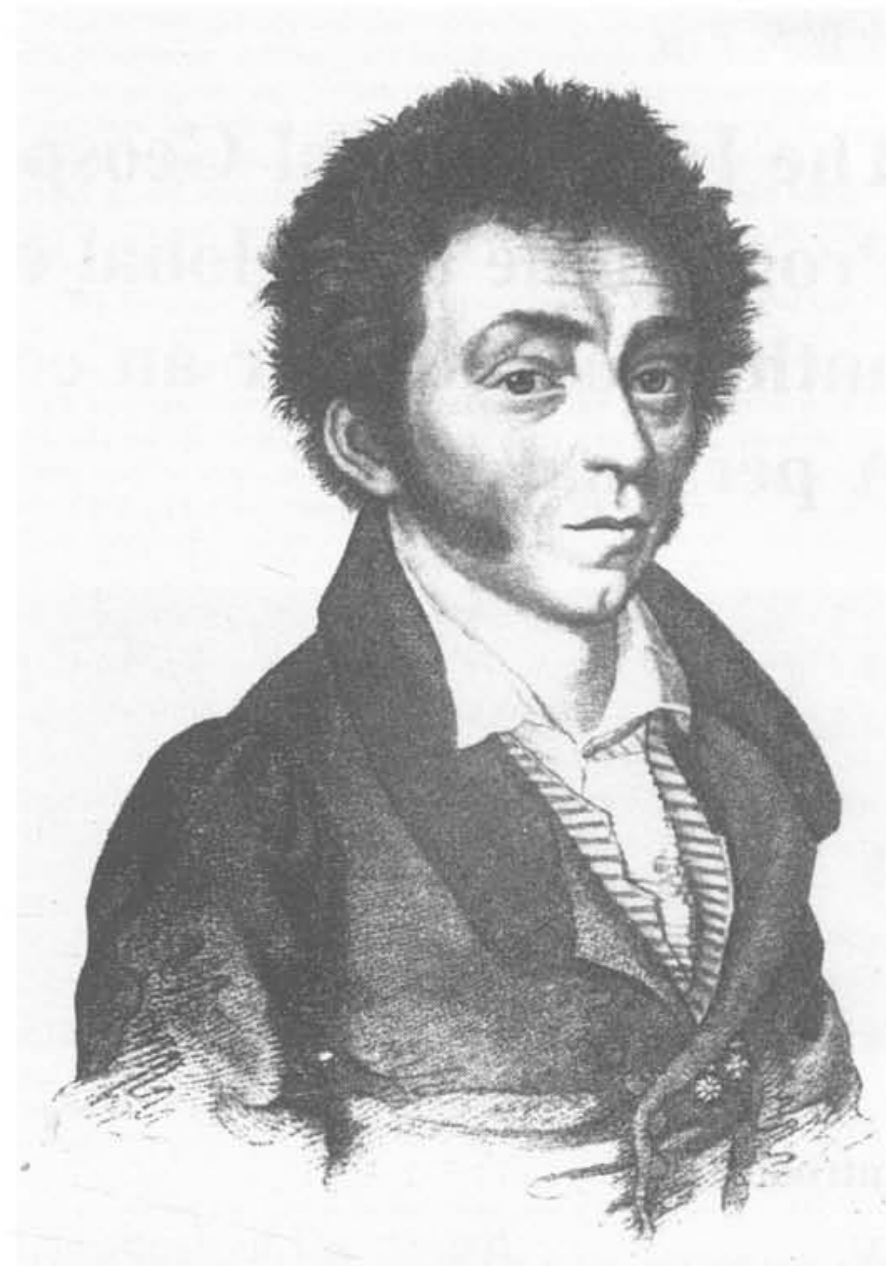

Figure 5. - Karl Caesar von Leonhard as a young man. He named "Löss" for the first time in Heidelberg, Germany, early in the 19th century. Not many pictures of this important pioneer exist, this one being from a paper by Franz Kirchheimer (see Smalley, 1980, p. 44, for details).

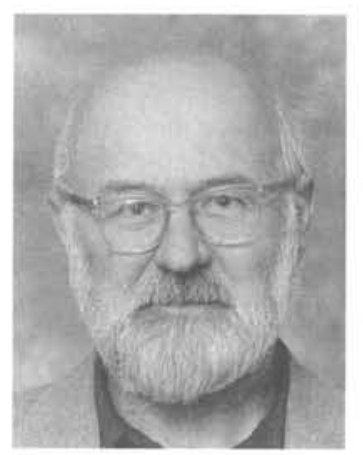

Dr. Ian Smalley is Secretary of the Centre for Loess Research and Documentation and honorary Professor of applied geomorphology at the University of Leicester, UK. He is Chairman of the documentation working group of the Loess Commission of the International Union for Quaternary Research, as well as Editor of Loess Letter. His research activities include the problems of loess particle forma tion and the nature of the large loess landslides in Gansu, PRC. Before moving to Leicester in 1986. he was Associate Professor of earth sciences at Waterloo University in Canada and Research Scientist at the New Zealand Soil Bureau. Born beside the Crayford Brickearths, he has been associated with loess all his life. 